\title{
BMJ Open Caesarean sections in teaching hospitals: systematic review and meta-analysis of hospitals in 22 countries
}

\author{
Ilir Hoxha (D) , ,2,3 Esra Zhubi, ${ }^{3}$ Krenare Grezda, ${ }^{3}$ Blerta Kryeziu, ${ }^{2}$ Jeta Bunjaku, ${ }^{3}$ \\ Fitim Sadiku, ${ }^{3}$ Riaz Agahi (D) , ${ }^{2}$ Daniel Adrian Lungu (D) , ${ }^{4}$ Manila Bonciani, ${ }^{4}$ \\ George Little
}

To cite: Hoxha I, Zhubi E, Grezda K, et al. Caesarean sections in teaching hospitals: systematic review and meta-analysis of hospitals in 22 countries. BMJ Open 2021;11:e042076. doi:10.1136/ bmjopen-2020-042076

- Prepublication history and additional material for this paper is available online. To view these files, please visit the journal online (http://dx.doi.org/10. 1136/bmjopen-2020-042076).

Received 29 June 2020

Revised 26 December 2020 Accepted 08 January 2021

Check for updates

(c) Author(s) (or their employer(s)) 2021. Re-use permitted under CC BY-NC. No commercial re-use. See rights and permissions. Published by BMJ.

${ }^{1}$ Department of Community \& Family Medicine, Geisel School of Medicine at Dartmouth, Hanover, New Hampshire, USA ${ }^{2}$ Research Unit, Heimerer College, Prishtina, Kosovo ${ }^{3}$ LifestylediagnostiX, Prishtina, Kosovo

${ }^{4}$ Health and Management Laboratory (MeS Lab), Institute of Management and Department EMbeDS, Scuola Superiore Sant'Anna, Pisa, Italy

${ }^{5}$ Department of Pediatrics and of Obstetrics and Gynecology, Geisel School of Medicine at Dartmouth, Hanover, New Hampshire, USA

Correspondence to

Dr llir Hoxha;

ilir.s.hoxha@gmail.com

\section{ABSTRACT}

Objective The aim of this study is to determine the odds of caesarean section in all births in teaching hospitals as compared with non-teaching hospitals.

Setting Over 3600 teaching and non-teaching hospitals in 22 countries. We searched CINAHL, The Cochrane Library, PubMed, sciELO, Scopus and Web of Science from the beginning of records until May 2020.

Participants Women at birth. Over 18.5 million births. Intervention Caesarean section.

Primary and secondary outcome measures The primary outcome measures are the adjusted $\mathrm{OR}$ of caesarean section in a variety of teaching hospital comparisons. The secondary outcome is the crude $\mathrm{OR}$ of caesarean section in a variety of teaching hospital comparisons.

Results In adjusted analyses, we found that university hospitals have lower odds than non-teaching hospitals ( $\mathrm{OR}=0.66,95 \% \mathrm{Cl} 0.56$ to 0.78 ) and other teaching hospitals ( $0 \mathrm{R}=0.46,95 \% \mathrm{Cl} 0.24$ to 0.89 ), and no significant difference with unspecified teaching status hospitals ( $\mathrm{OR}=0.92,95 \% \mathrm{Cl} 0.80$ to $1.05, \tau 2=0.009$ ). Other teaching hospitals had higher odds than non-teaching hospitals ( $O R=1.23,95 \% \mathrm{Cl} 1.12$ to 1.35 ). Comparison between unspecified teaching hospitals and non-teaching hospitals $(0 \mathrm{R}=0.91,95 \% \mathrm{Cl} 0.50$ to $1.65, \tau 2=1.007$ ) and unspecified hospitals ( $\mathrm{OR}=0.95,95 \% \mathrm{Cl} 0.76$ to 1.20 ), $\tau 2<0.001)$ showed no significant difference. While the main analysis in larger sized groups of analysed studies reveals no effect between hospitals, subgroup analyses show that teaching hospitals carry out fewer caesarean sections in several countries, for several study populations and population characteristics.

Conclusions With smaller sample of participants and studies, in clearly defined hospitals categories under comparison, we see that university hospitals have lower odds for caesarean. With larger sample size and number of studies, as well as less clearly defined categories of hospitals, we see no significant difference in the likelihood of caesarean sections between teaching and non-teaching hospitals. Nevertheless, even in groups with no significant effect, teaching hospitals have a lower or higher likelihood of caesarean sections in several analysed subgroups. Therefore, we recommend a more precise examination of forces sustaining these trends.

PROSPERO registration number CRD42020158437.
Strengths and limitations of this study

- The major strengths of our systematic review and meta-analysis include a broad literature search, data extraction performed by more than one reviewer, an exploration of study characteristics as a potential source of variation between studies and quality assessment using Quality in Prognosis Studies tool.

- Some additional strengths of this study are the large sample size and the inclusion of many hospitals over broad geographic regions.

- Potential limitations relate to differences in the characteristics of compared hospitals, study populations, type of data used, types of caesarean section analysed and variables used for adjustment in statistical analyses across studies.

- We also lack information on hospital resources, infrastructure and staffing of compared hospitals which could have been useful for a more detailed analysis of the underlying factors that may contribute to differences among teaching and non-teaching hospitals.

\section{INTRODUCTION}

Caesarean sections (CSs) are a key surgical procedure in improving long-term health outcomes in high-risk births. ${ }^{1}{ }^{2}$ Key to providing high quality healthcare is avoiding the risks associated with using this procedure in low-risk pregnancies. Despite recommendations by the WHO to decrease CS rates and perform CS based primarily on medical indications, ${ }^{3-5} \mathrm{CS}$ rates continue to increase, rising to an estimated $21.1 \%$ worldwide in 2015 . $^{6}$ Furthermore, there is a large degree of variation observed. The rate in different countries ranges from dangerously low, that is, below $10 \%$, to extraordinary high rates, for example, $58.1 \%$ in the Dominican Republic. ${ }^{6}$ Within country variations have also been observed in many countries including the USA. $^{7}$ More recently, in Italy, the 2018 data concerning nulliparous, term, singleton, vertex CS show variation between $8.4 \%$ and 
$44.4 \%$ among health authorities, with significant and constant intra-regional variation. ${ }^{8}$

It is highly unlikely that such dramatic differences are explained solely by clinical factors. They may stem from a variety of factors, such as insurance status or socioeconomic background. ${ }^{9-13}$ Factors affecting patient or clinician preferences may also be responsible for variations in healthcare delivery. Patients prefer caesareans for cultural-related or experience-related reasons. Physicians can be less skilled in relation to natural birth, in comparison to, for example, midwives. ${ }^{14-21}$ Hospital factors may also have an effect. ${ }^{10223}$

Hospital teaching status is one of hospital characteristics that may explain the variability of CS among hospitals. In general, teaching hospitals are known to have higher overall rates of surgery, which is perhaps reflective of more complex caseloads. ${ }^{24-26}$ For this reason, it may be intuitively assumed that teaching hospitals have a higher proportion of high-risk births and, as such, higher likelihood of CS. But this doesn't seem to be the case with CSs. Teaching hospitals are generally associated with a higher standard of care and better outcomes. ${ }^{26-32}$ There is more adherence to evidence-based guidelines and/or clinical protocols. Higher quality care, in turn, can also translate to a lower likelihood of caesarean delivery as a result of fewer unnecessary procedures. Teaching hospitals also generally have access to a certain level of technology, and it is easier to apply protective measures, such as requiring a second opinion on CS procedures. ${ }^{27}$ The goal of this review is to examine the odds of CS in teaching and nonteaching hospitals. We aim to determine whether there is a significant difference, evaluate the effect size and variations among different groups and subgroups, and thereby understand the differences in delivery care provision between teaching and non-teaching hospitals.

\section{MATERIALS AND METHODS}

This meta-analysis was constructed as per previous metaanalyses carried out by members of our group ${ }^{22} 33-35$ and in accordance with the structure suggested by Dekkers and coworkers, ${ }^{36}$ the Preferred Reporting Items for Systematic Reviews and Meta-Analyses guidelines ${ }^{37}$ and Meta-analysis of Observational Studies in Epidemiology guidelines for meta-analysis of observational studies. ${ }^{38} \mathrm{We}$ produced a protocol, which was submitted and registered with PROSPERO.

\section{Eligibility criteria, information sources, search strategy}

In order to get the widest spread of data possible, we searched CINAHL, The Cochrane Library, PubMed, sciELO, Scopus and Web of Science from the beginning of records until May 2020. The search terms were based on a four-level strategy, with terms related to CSs, terms related to hospital teaching status, terms related to area of research, that is, health system variation and so on, and terms related to study design.

\section{Study selection}

The primary criterion for study inclusion was the presence of an OR for CSs in teaching and non-teaching hospitals. Reports which included other data (ie, regression coefficients, case data by type of hospital and delivery outcome) allowing the ORs to be calculated were also included. Study inclusion was also contingent on study design, targeting in this reviews, systematic reviews, cohort studies and cross-sectional studies. Studies were excluded to remove overlapping data. This refers to the situation where more than one identified article (during screening/full-text review) seems to have used same data sets. Studies were also excluded in case they were not reported in English language. The eligibility of each study was assessed independently by at least two researchers, and disagreements were resolved by consultation.

\section{Data extraction}

Data extraction was carried out by at least two independent researchers for each study. Another reviewer performed a final review of all extracted data. Disagreements were resolved by discussion. A data extraction spreadsheet was constructed to facilitate the process, and included a number of pertinent data, such as publication data, effect estimate, confidence limits, main determinant being studied and sample size, among other data. For the purpose of classification of population of each study, we extracted exclusion/inclusion criteria data that were used by authors in order to specify their study population. Such data enabled us to classify population for each study based on Robson system. Robson's 10 group classification system is based on five main population features including obstetric history, onset of labour, presentation of features, number of neonates and gestational age. ${ }^{39}$ This is a standardised comparison method that is helpful and widely used to analyse trends and determinants of $\mathrm{CS}^{40}$

\section{Assessment of risk of bias}

The risk of bias for included studies was assessed in terms of six domains-study participation, study attrition, prognostic factor measurement, study confounding, and statistical analysis and reporting, using the Quality in Prognosis Studies (QUIPS) tool. ${ }^{41}$ Although it is a standardised tool for prognostic studies, it fits very well with overall structure of included papers and it has already been used in methodologically similar reviews. ${ }^{32} 3335$

\section{Data synthesis}

The ORs were combined using standard inverse-variance random-effects meta-analysis, where an OR lower than one shows a lower likelihood of CS in teaching hospitals than non-teaching hospitals. ${ }^{42}$

Using definitions and classifications provided by Ayanian and Weissman ${ }^{43}$ as well as definitions used by papers included in the review, we specified three main categories of hospitals: University hospital, other teaching hospital and non-teaching hospital. University hospital 
is a major teaching hospital affiliated with a medical school. ${ }^{43}$ It is the institution where residency programmes take place, high-end care is provided and research activity takes place. Other teaching hospitals do not meet such criteria, but they do provide residency training. ${ }^{43}$ Nonteaching hospitals are hospitals that do not provide venue for training of residents. In case studies were not clear on the definition of comparing hospitals, we marked them as unspecified teaching or as unspecified hospital. In case where studies did not specify to which type of teaching hospitals they were referring to, we marked them as unspecified teaching hospital. In such cases, it is highly likely, that is, studies for USA, that such category of hospitals includes both university and other teaching hospitals. In case where studies did not specify reference hospital, we marked them as unspecified hospital. Based on our assessment, such categorisation of hospitals is likely to include both non-teaching hospitals or other teaching hospitals or one of them.

As a result, based on classification of teaching hospitals and reference hospitals studies used, we analysed adjusted and crude estimates reported by studies independently in six different groups: university versus non-teaching hospital, university versus other teaching hospital, university versus unspecified hospital, other teaching versus nonteaching hospital, unspecified teaching hospital versus non-teaching hospital, unspecified teaching hospital versus unspecified hospital.

Subgroup analysis for adjusted estimates by country, study design, period of data collection, population by Robson groups and criteria, type of CS analysed, type of data used and level of (QUIPS) risk of bias domains was used to examine between-study heterogeneity and $\chi^{2}$ test used to calculate $\mathrm{p}$ values for interaction among subgroups.

Statistical analysis was carried out using STATA, release V.15 (StataCorp).

\section{Patient involvement}

No patients were involved in this study. We used data from published papers only.

\section{RESULTS}

\section{Study selection}

We identified a total of 5233 records: 344 from CINAHL, 1049 from the Cochrane Library, 1522 from PubMed, 651 from sciELO, 534 from Scopus, 1133 from Web of Science. Additional 68 records were identified from a manual search (figure 1). We removed 783 duplicates; 4518 records were screened for eligibility. We performed full-text examination on 908 records. We excluded 827 that did not report hospital teaching status, 46 that were otherwise irrelevant and three records with overlapping populations. Finally, 32 records describing 32 separate studies ${ }^{18}{ }^{27} 44-73$ including 18.5 million births in 22 different countries, were included in the review and meta-analysis. Of these, 18 studies were included in the meta-analyses of adjusted ORs and 27 studies were used in the meta-analyses of crude ORs.

\section{Study characteristics}

Characteristics of included studies are shown in table 1 and online supplemental appendix 1. Most included studies were retrospective studies, with some prospective studies also included. The studies were from a variety of countries and health systems. Sample size varied from 214 to 8.48 million births. The oldest study was from 1991, but the vast majority of included studies were carried out post-2000. Case exclusion criteria and covariates for statistical adjustment also varied considerably (online supplemental appendix 1).

\section{Risk of bias of included studies}

The main potential source of bias is study confounding, where 17 of the 32 studies included had a high risk of bias and 9 studies had a moderate risk of bias. With respect to study participation, four studies had a moderate risk of bias, with the remainder having a low risk of bias. A low risk of bias in all studies was reported for study attrition, prognostic factor measurement and outcome measurement, while only two studies had a moderate risk of bias for the statistical analysis and reporting domain.

\section{Synthesis of results}

Figure 2 presents meta-analyses for primary outcome measures, that is, adjusted ORs for all six groups we analysed. In the first group, including one study, university hospitals had lower odds of CS than non-teaching hospitals (OR $=0.66,95 \%$ CI 0.56 to 0.78$)$. Similarly, in second group, university hospitals CS was 0.46 times as likely than in other teaching hospitals (95\% CI 0.24 to 0.89 ). In the third comparison group involving three studies, university hospitals did not have significantly different odds of CS compared with unspecified hospitals (OR $=0.92,95 \%$ CI 0.80 to 1.05 ) with low heterogeneity between studies $(\tau 2=0.009)$. Analysis of the group of other teaching hospitals in comparison with non-teaching hospitals from one study showed higher odds of $\mathrm{CS}(\mathrm{OR}=1.23,95 \%$ CI 1.12 to 1.35). Comparison group of unspecified teaching hospitals with non-teaching hospitals, which incorporated 11 studies and was the largest adjusted analysis, showed no significant difference $(\mathrm{OR}=0.91,95 \%$ CI 0.50 to 1.65$)$ with high heterogeneity between studies $(\tau 2=1.007)$. Similarly, including three studies, unspecified teaching hospitals did not have significantly lower odds than unspecified hospitals (OR=0.95, 95\% CI 0.76 to 1.20$)$ with no heterogeneity between studies $(\tau 2<0.001)$.

Subgroup analyses of adjusted ORs in teaching and non-teaching hospitals (online supplemental appendix 1) showed some variation. For the comparison of university hospitals and unspecified hospitals, lower odds of CS were observed for France ( $\mathrm{OR}=0.84,95 \% \mathrm{CI} 0.74$ to 0.97 ), while for USA the odds were the same $(\mathrm{OR}=1.00,95 \%$ CI 0.95 to 1.06 ). Lower odds were observed also in the subgroup with single number of fetuses, studies with low 


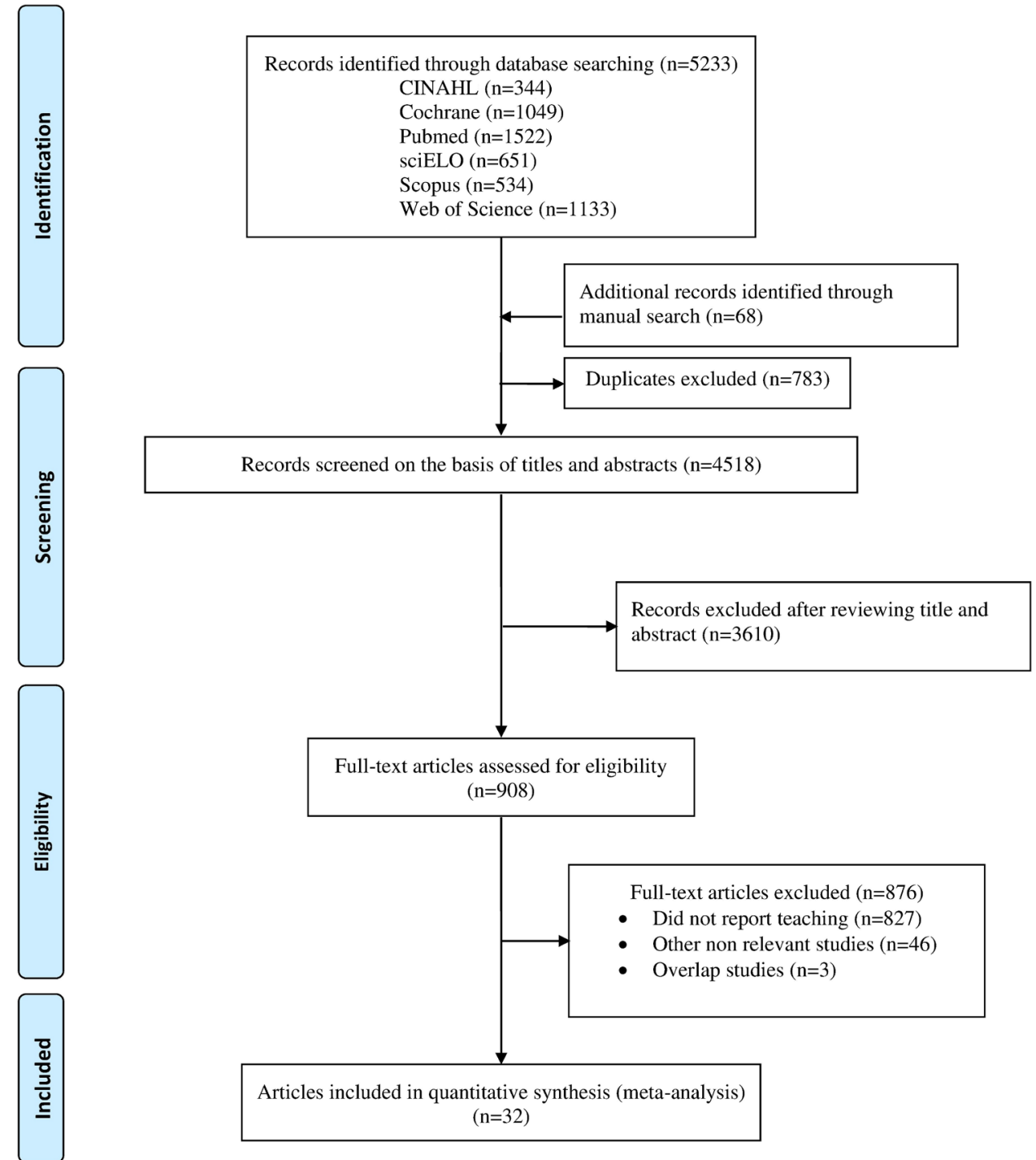

Figure 1 The flow diagram of review.

risk of confounding (as defined by QUIPS), studies using hospital data, as well as studies not using birth registry data.

Subgroup analysis for the comparison of unspecified teaching hospitals with non-teaching hospitals highlighted difference in many factors. Inter-country variation was particularly notable, where France $(\mathrm{OR}=0.30$, $95 \%$ CI 0.16 to 0.58$)$, Palestine (OR=0.53, $95 \%$ CI 0.37 to $0.77)$, Taiwan ( $\mathrm{OR}=0.86,95 \%$ CI 0.82 to 0.91$)$ and USA ( $\mathrm{OR}=0.80,95 \% \mathrm{CI} 0.72$ to 0.88 ) had lower odds of CS. Conversely, Korea (OR=4.95, 95\% CI 4.82 to 5.09) and Lebanon ( $\mathrm{OR}=1.40,95 \%$ CI 1.30 to 1.50$)$ had higher odds of CS in teaching hospitals. There was also variation in Robson subgroups. Studies using groups 1 and 3 showed lower odds of $\mathrm{CS}$ in teaching hospitals $(\mathrm{OR}=0.80,95 \% \mathrm{CI}$ 0.69 to 0.93$)$, as did studies with mothers from groups 6 and $7(\mathrm{OR}=0.30,95 \% \mathrm{CI} 0.16$ to 0.58$)$. Conversely, studies using all Robson subgroups had higher odds of CS $(\mathrm{OR}=4.95,95 \%$ CI 4.82 to 5.09). There was also variation in OR with studies including different fetal presentation, where studies with any fetal presentation showed no difference (OR=1.04, 95\% CI 0.50 to 2.14), studies including breach presentation showed lower odds of CS $(\mathrm{OR}=0.30,95 \% \mathrm{CI} 0.16$ to 0.58$)$ and odds of 0.88 were observed for cephalic presentation $(95 \% \mathrm{CI}, 0.75$ to $1.04)$. Studies with high $(1.57,95 \%$ CI 0.39 to 6.32$)$ and low $(1.15,95 \%$ CI 0.79 to 1.69$)$ QUIPS confounding showed no significant difference in odds, while studies with moderate risk of confounding had lower odds of CS $(0.73,95 \%$ CI 0.69 to 0.78$)$.

In secondary outcome analysis (figure 3), CS in university hospitals was 1.36 times as likely as compared with non-teaching hospitals, although the difference was not significant (95\% CI 0.80 to $2.32, \tau 2=0.208)$, and 0.50 times as likely in comparison with other teaching hospitals (95\% CI 0.35 to 0.71$)$. In comparison with unspecified hospitals, there was again no significant difference $(\mathrm{OR}=1.01,95 \% \mathrm{CI} 0.86$ to 1.17$)$ with low heterogeneity between studies $(\tau 2=0.019)$. CS was 1.28 times as likely in other teaching hospitals compared with non-teaching hospitals (95\% CI 1.11 to 1.46 ) with no relevant heterogeneity between studies $(\tau 2=0.009)$. Our unadjusted 


\section{¿্ড}

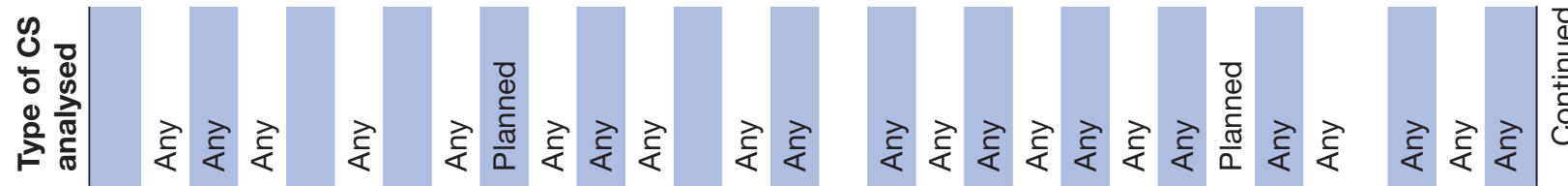

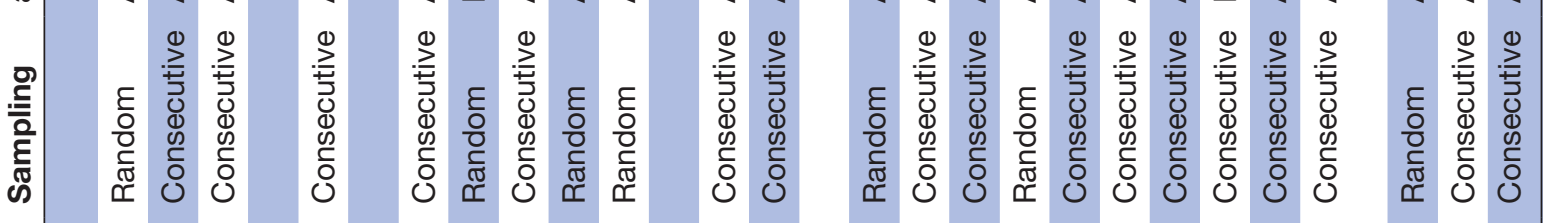

흥

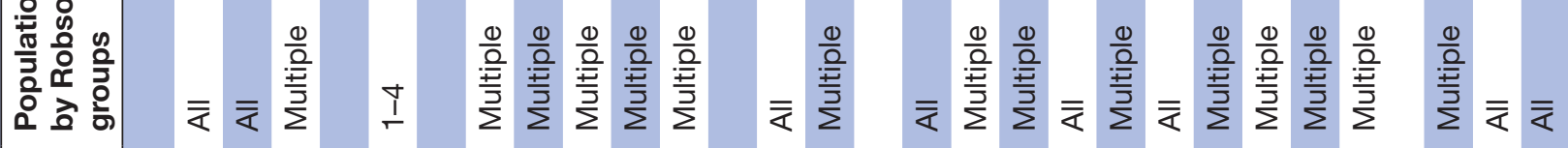

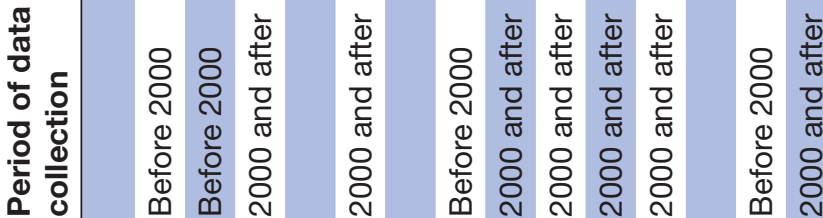

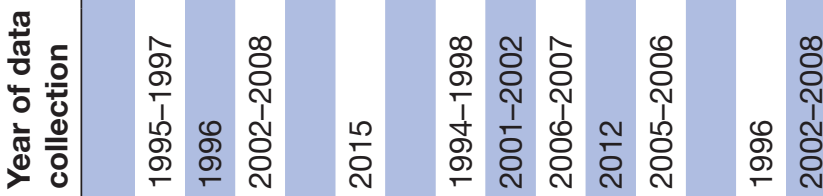

क्षे

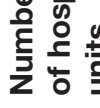

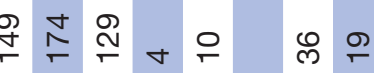

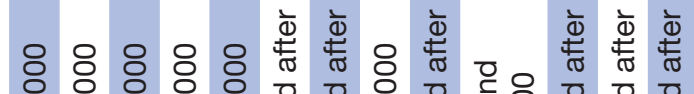

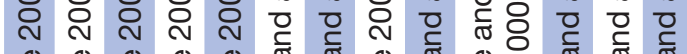

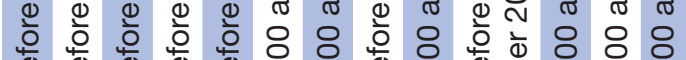

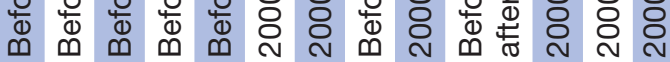

$\stackrel{\infty}{\stackrel{\infty}{\circ}}$

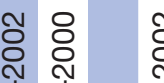

유

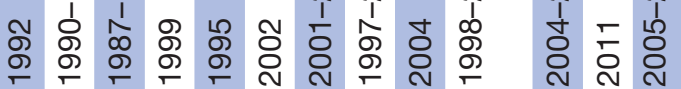

(1)

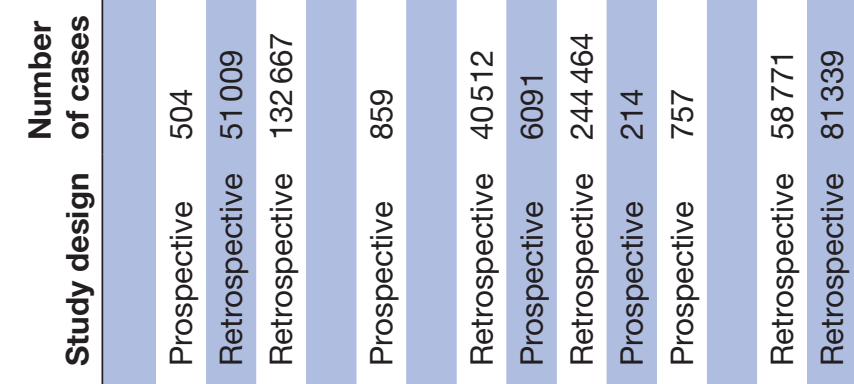

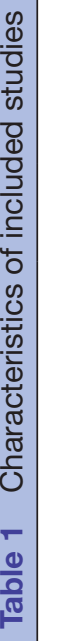

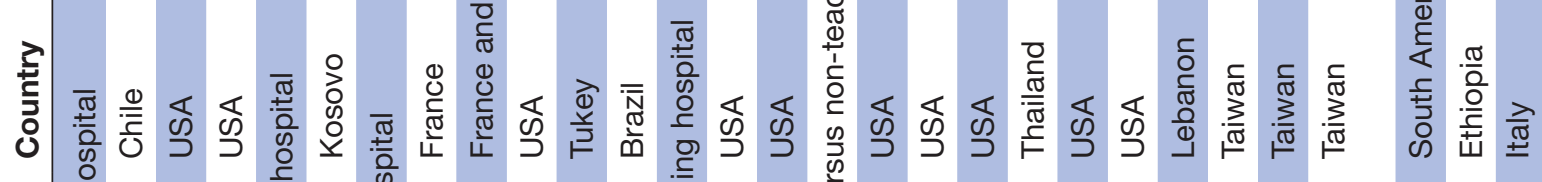

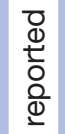

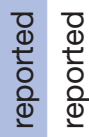

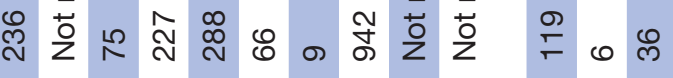

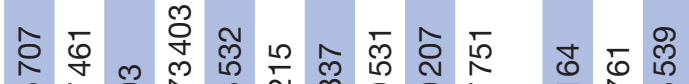

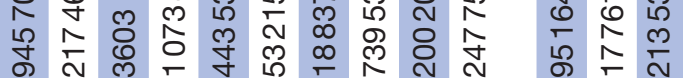

0000000000

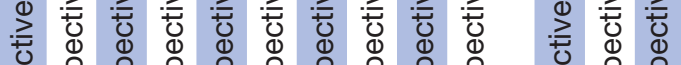

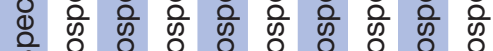

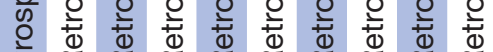

ब.

일 区

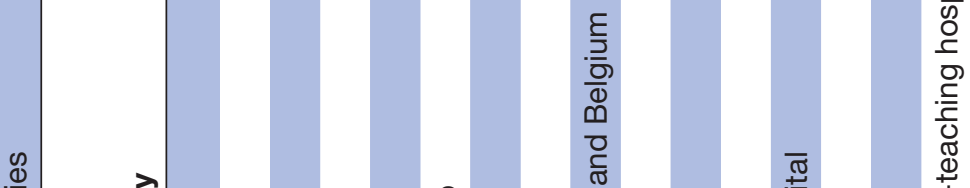

高

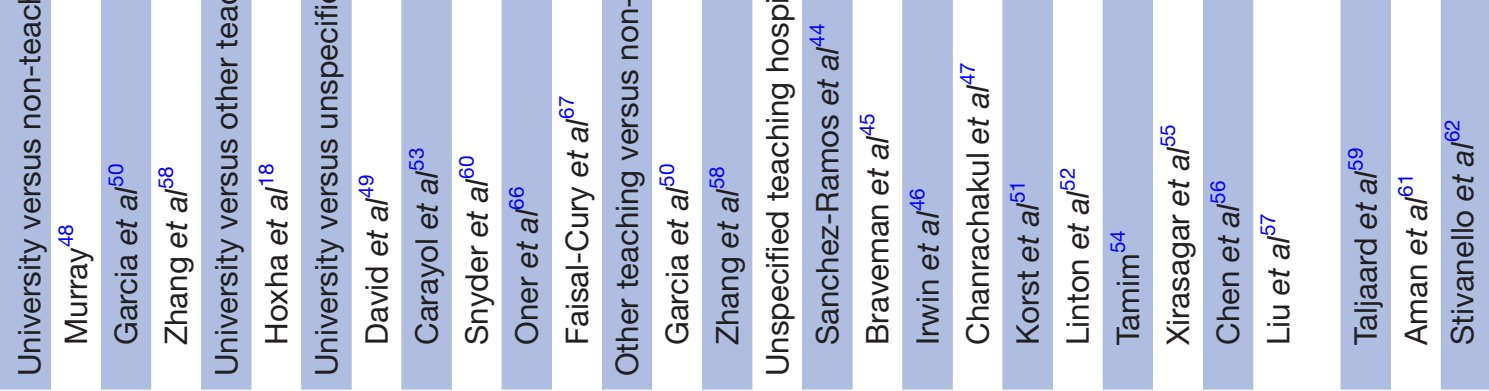




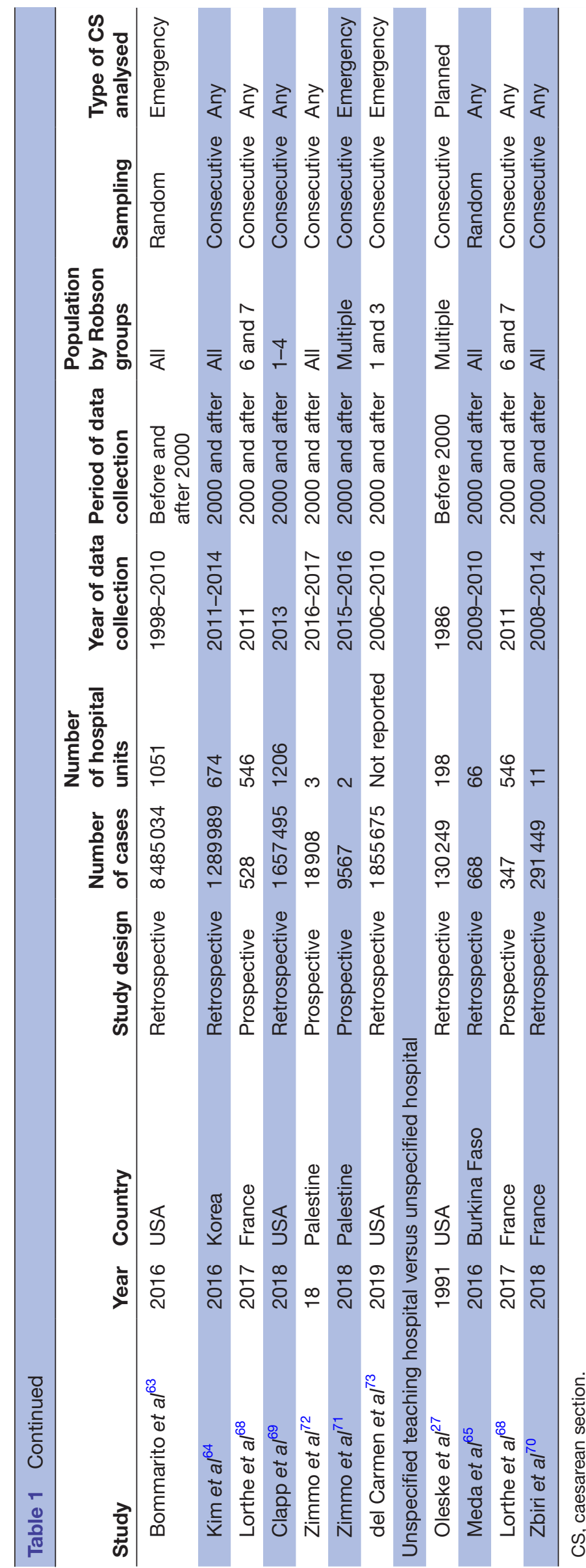




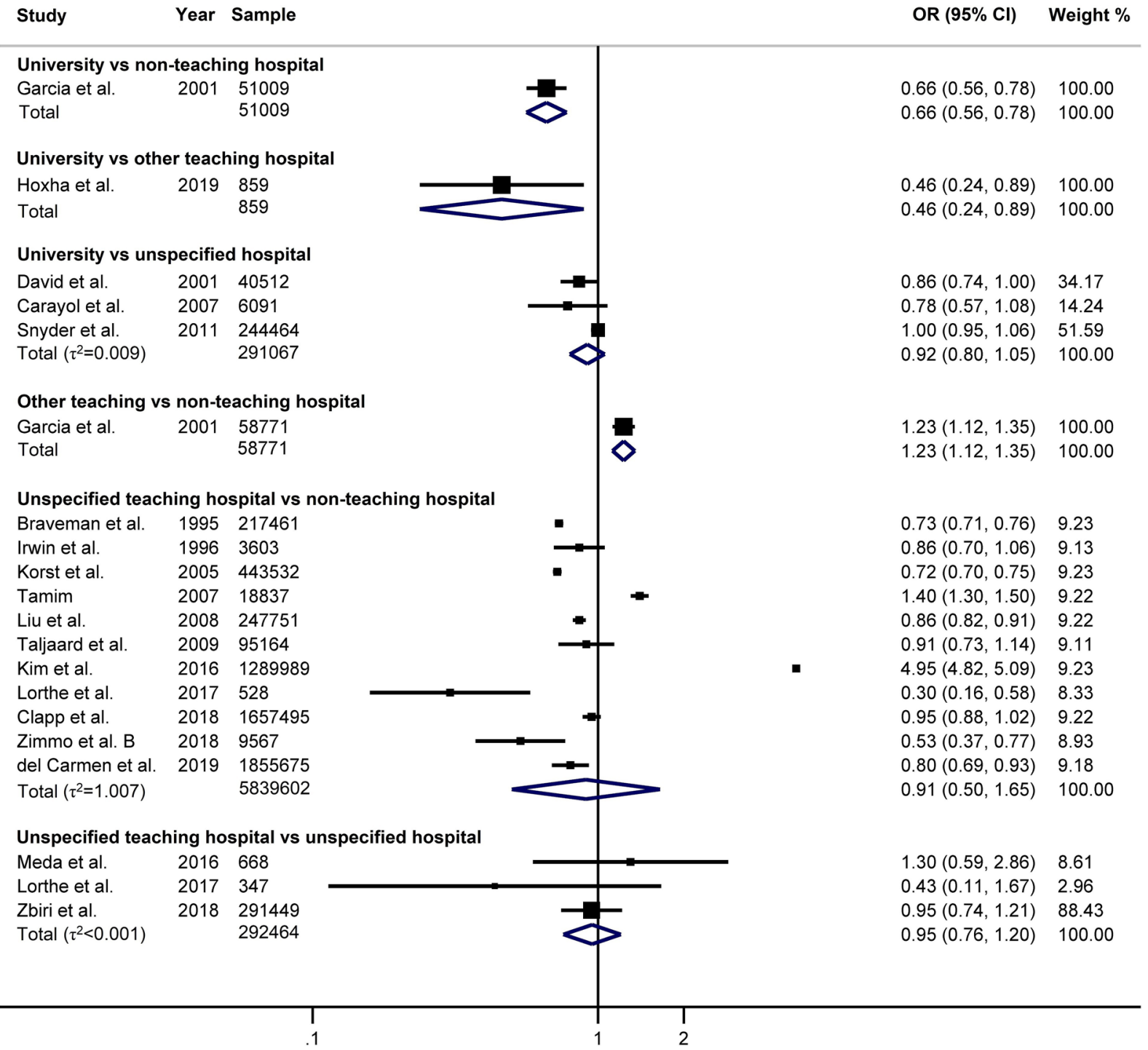

Figure 2 Adjusted ORs of caesarean section.

comparisons of unspecified types of teaching hospital with non-teaching hospitals and unspecified hospitals reflected the results of the adjusted analysis, with no significant difference observed. In the case of nonteaching hospitals, CS was 1.01 times as likely (95\% CI 0.63 to 1.61 ) with high heterogeneity between studies $(\tau 2=0.859)$. For unspecified teaching hospitals, in comparison with unspecified hospitals, there was no significant difference in the odds of CS $(\mathrm{OR}=0.96$, $95 \%$ CI 0.85 to 1.09 ) with no relevant heterogeneity between studies $(\tau 2=0.006)$.

\section{DISCUSSION}

In more clearly defined hospital comparison groups, we see lowering effect of teaching hospitals as compared with non-teaching hospitals. But samples and number of studies are small. In most of the studies and largest sample size, we see no overall significant difference between teaching and non-teaching hospitals in adjusted and subgroup analyses. Subgroup analyses showed varied estimates.

\section{Strengths and weaknesses}

The major strengths of our systematic review and metaanalysis include a broad literature search, data extraction performed by more than one reviewer, an exploration of study characteristics as a potential source of variation between studies and quality assessment using QUIPS. Some additional strengths of this study are the very large sample size and the inclusion of many hospitals over broad geographic regions. Potential limitations which may have affected inconsistencies in the results relate to differences in the characteristics of compared hospitals, study populations, type of data used, types of CS analysed and variables used for adjustment in statistical analyses across studies. The fact that most studies have not been as precise in definition of specific categories of teaching status of hospital is particularly limiting. Moreover, we lack information on hospital resources, infrastructure 


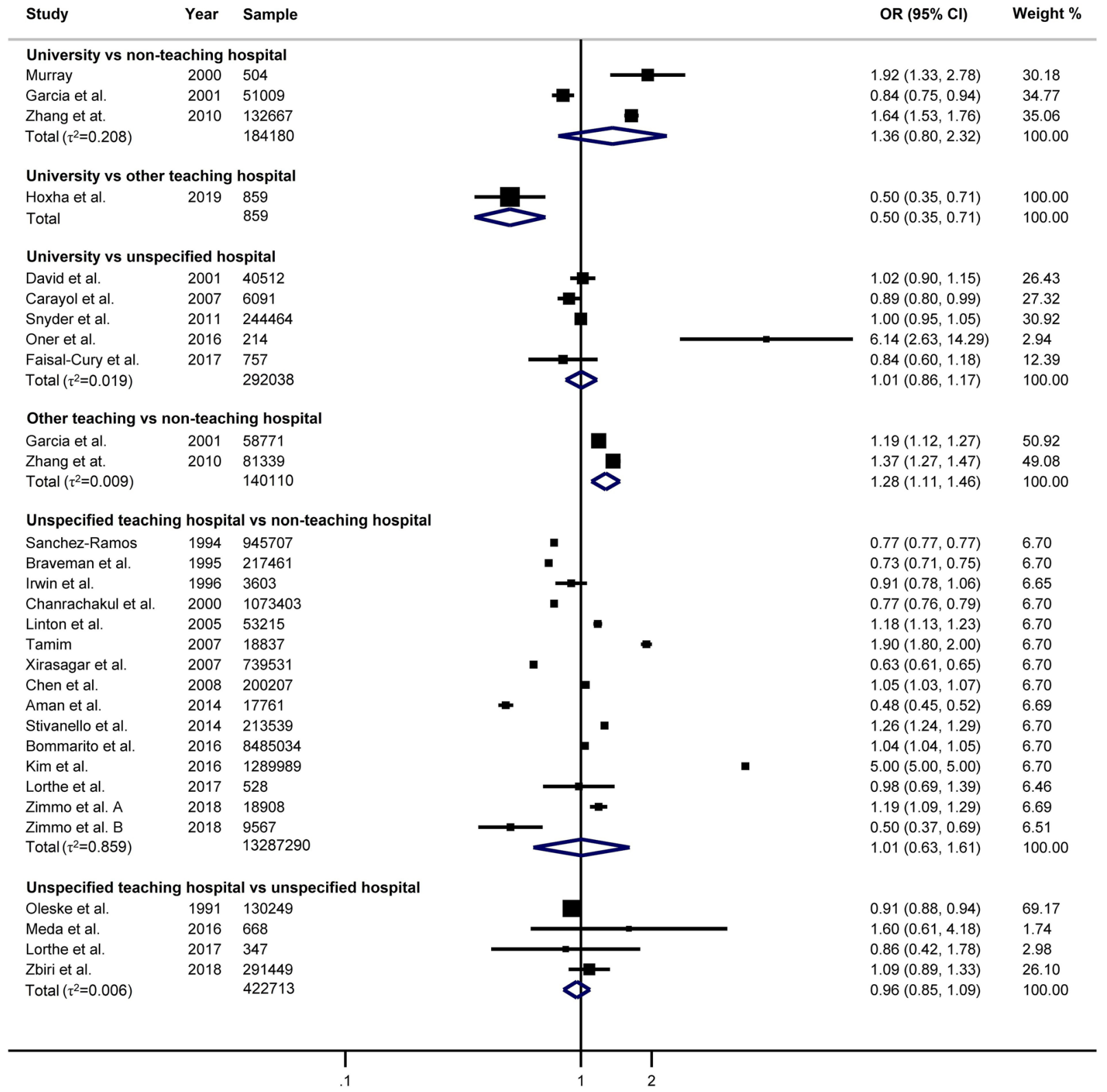

Figure 3 Crude ORs of caesarean section.

and staffing, all of which could contribute to maternal outcomes and risk for CS. ${ }^{7}$

\section{Context}

The findings in this study demonstrate the complexity of the interactions of many factors. The role of health system factors in general and hospital factors in particular should not be ignored. Recent meta-analyses examining the effect of hospitals and financial factors ${ }^{22} 3334$ have found that CS was 1.41 times as likely in for-profit hospitals as compared with non-profit hospitals (95\% CI 1.24 to $1.60),{ }^{22} 1.13$ for privately insured women compared with women covered with public insurance (95\% CI 1.07 to $1.18)^{34}$ and 0.70 in uninsured as compared with privately and publicly insured women (95\% CI 0.69 to 0.72$){ }^{33}$

\section{Interpretation}

The findings in our group and subgroup analyses indicate that the effect of hospital teaching status varies between countries, study design and confounders considered in data analysis. Specific populations of mothers and particular type of CS are also important variables in examining the effect of hospital variation. Patient populations in teaching versus non-teaching hospitals are generally very different in terms of underlying medical conditions and obstetric risk, which would likely drive any differences observed in odds for CS. Hence, intuitively, we would expect that odds for CS are likely to be higher in teaching hospitals, where more complex cases are often taken. Our study does not show this, and in several 
groups and subgroups the opposite is observed. Variation in odds of CS in teaching hospitals for particular Robson groups hints at differences in implementation of clinical standards. Studies have suggested that the lower odds in teaching hospitals may be due to availability of resources, ${ }^{44} 74$ access to technology, ${ }^{75}$ closer supervision and care ${ }^{60}$ stronger accountability, ${ }^{76}$ adherence to clinical standards ${ }^{18} 27577778$ and professional consultation opportunities. ${ }^{27}$

\section{Implications}

Our study contributes to understanding of the role of hospital-related causes on the rates of CS. It may also provide an impetus for further research, particularly setting-specific studies, or even individual patient data meta-analysis. Such studies would allow a more precise and in-depth analysis of the characteristics of hospitals associated with teaching status, such as resource availability or adherence to clinical guidelines. In order to improve the quality of healthcare provision for deliveries, the interplay of factors related to teaching status of hospitals must be examined, in all outcomes of related to deliveries, including but not limited to overall CS, emergency and primary caesarean, vaginal birth after caesarean. Using classification by Robson groups or primary CS will help in understanding better the implications of results in future studies. Using variables with information such as infrastructure and other facets of hospital variation could be useful to elucidate more clearly the mechanism. Another way to understand the underlying factors related to hospital characteristics, which is being applied in Tuscany (Italy), is to put in place systematic and ongoing collection of Patient-Reported Experience Measures and Patient-Reported Outcome Measures ${ }^{79}$ which could ensure continuous source of data to measure hospital performance outcomes.

\section{CONCLUSION}

With smaller sample of participants and studies, in clearly defined hospitals categories under comparison, we see that university hospitals have lower odds for caesarean. With larger sample size and number of studies, in less clearly defined categories of hospitals, we see no significant difference in the likelihood of CSs between teaching and non-teaching hospitals. Nevertheless, even in groups with no significant effect, teaching hospitals in many subgroups, have a lower likelihood of CSs. Lower or higher odds for CS among teaching hospitals hint at the effect of important aspects of healthcare delivery. Hence, further research would help to understand the interplay of underlying factors in individual settings which may provide useful insights for policy or medical practice efforts to ensure appropriate and efficient use of delivery care.

Acknowledgements We thank Melisa Uka for graphic design of figures, Altina Bimbashi and Dorentina Kuqi for technical assistance with data. No direct funding was received to perform this study. All authors had full access to all of the data (including statistical reports and tables) in the study and take responsibility for the integrity of the data and the accuracy of the data analysis. All authors have completed the ICMJE uniform disclosure form at www.icmje.org/coi_disclosure.pdf and declare: no support from any organisation for the submitted work; no financial relationships with any organisations that might have an interest in the submitted work in the previous three years; no other relationships or activities that could appear to have influenced the submitted work.

Contributors $\mathrm{IH}$ conceived and designed the study. BK, JB, FS performed the screening of studies. IH, EZ, KG, BK, JB, FS performed the data extraction and preparation. IH and EZ performed quality assessment of studies. IH has analysed the data. DAL, MB and GL have contributed to the interpretation of findings. IH, EZ and RA drafted the paper, which was critically reviewed and approved by all authors.

Funding The authors have not declared a specific grant for this research from any funding agency in the public, commercial or not-for-profit sectors.

Competing interests None declared.

Patient consent for publication Not required.

Provenance and peer review Not commissioned; externally peer reviewed.

Data availability statement All data relevant to the study are included in the article or uploaded as supplementary information.

Supplemental material This content has been supplied by the author(s). It has not been vetted by BMJ Publishing Group Limited (BMJ) and may not have been peer-reviewed. Any opinions or recommendations discussed are solely those of the author(s) and are not endorsed by BMJ. BMJ disclaims all liability and responsibility arising from any reliance placed on the content. Where the content includes any translated material, BMJ does not warrant the accuracy and reliability of the translations (including but not limited to local regulations, clinical guidelines, terminology, drug names and drug dosages), and is not responsible for any error and/or omissions arising from translation and adaptation or otherwise.

Open access This is an open access article distributed in accordance with the Creative Commons Attribution Non Commercial (CC BY-NC 4.0) license, which permits others to distribute, remix, adapt, build upon this work non-commercially, and license their derivative works on different terms, provided the original work is properly cited, appropriate credit is given, any changes made indicated, and the use is non-commercial. See: http://creativecommons.org/licenses/by-nc/4.0/.

\section{ORCID iDs}

Ilir Hoxha http://orcid.org/0000-0003-4262-1406

Riaz Agahi http://orcid.org/0000-0001-5497-7886

Daniel Adrian Lungu http://orcid.org/0000-0002-8612-8384

\section{REFERENCES}

1 Biccard BM, Madiba TE, Kluyts H-L, et al. Perioperative patient outcomes in the African surgical outcomes study: a 7-day prospective observational cohort study. Lancet 2018;391:1589-98.

2 Villar J, Carroli G, Zavaleta N, et al. Maternal and neonatal individual risks and benefits associated with caesarean delivery: multicentre prospective study. BMJ 2007;335:1025-25.

3 Appropriate technology for birth. The Lancet 1985;326:436-7.

4 WHO, HRP. WHO statement on cesarean section rates 2015.

5 Betran AP, Torloni MR, Zhang JJ, et al. WHO statement on caesarean section rates. BJOG 2016;123:667-70.

6 Boerma T, Ronsmans C, Melesse DY, et al. Global epidemiology of use of and disparities in caesarean sections. Lancet 2018;392:1341-8.

7 Hoxha I, Busato A, Luta X. Medical practice variations in reproductive, obstetric, and gynecological care. In: Johnson A, Stukel TA, eds. Medical practice variations. Boston, MA: Springer US, 2016: 141-60.

8 MeS Laboratory. Scuola Superiore Sant'Anna. performance evaluation system, 2020. Available: www.performance.sssup.it/netval

9 Boatin AA, Adu-Bonsaffoh K, Wylie BJ, et al. Evaluating FacilityBased decision-making in women with a prior cesarean delivery and association with maternal and perinatal outcomes. Matern Child Health J 2017;21:1845-52.

10 Stafford RS. The impact of nonclinical factors on repeat cesarean section. JAMA 1991;265:59-63.

11 Adler NEet al. Socioeconomic inequalities in health. JAMA 1993;269:3140-5. 
12 Cáceres IA, Arcaya M, Declercq E, et al. Hospital differences in cesarean deliveries in Massachusetts (US) 2004-2006: the case against case-mix artifact. PLoS One 2013;8:e57817.

13 Betran AP, Torloni MR, Zhang J, et al. What is the optimal rate of caesarean section at population level? A systematic review of ecologic studies. Reprod Health 2015;12:57.

14 Davis LG, Riedmann GL, Sapiro M, et al. Cesarean section rates in low-risk private patients managed by certified nurse-midwives and obstetricians. J Nurse Midwifery 1994;39:91-7.

15 Wang Z, Sun W, Zhou H. Midwife-led care model for reducing caesarean rate: a novel concept for worldwide birth units where standard obstetric care still dominates. Journal of Medical Hypotheses and Ideas 2012;6:28-31.

16 McLachlan HL, Forster DA, Davey MA, et al. Effects of continuity of care by a primary midwife (caseload midwifery) on caesarean section rates in women of low obstetric risk: the Cosmos randomised controlled trial. BJOG 2012;119:1483-92.

17 Kearney L, Kynn M, Craswell A, et al. The relationship between midwife-led group-based versus conventional antenatal care and mode of birth: a matched cohort study. BMC Pregnancy Childbirth 2017; $17: 39$

18 Hoxha I, Fejza A, Aliu M, et al. Health system factors and caesarean sections in Kosovo: a cross-sectional study. BMJ Open 2019;9:e026702.

19 Metz TD, Allshouse AA, Gilbert SAB, et al. Variation in primary cesarean delivery rates by individual physician within a singlehospital laborist model. Am J Obstet Gynecol 2016;214:531.e1-531. e6.

20 Fabbri D, Monfardini C, Castaldini I, et al. Cesarean section and the manipulation of exact delivery time. Health Policy 2016;120:780-9.

21 Gonen R, Tamir A, Degani S. Obstetricians' opinions regarding patient choice in cesarean delivery. Obstet Gynecol 2002;99:577-80.

22 Hoxha I, Syrogiannouli L, Luta X, et al. Caesarean sections and forprofit status of hospitals: systematic review and meta-analysis. $B M J$ Open 2017;7:e013670.

23 Borrescio-Higa F, Valdés N. Publicly insured caesarean sections in private hospitals: a repeated cross-sectional analysis in Chile. BMJ Open 2019;9:e024241.

24 Frick AP, Martin SG, Shwartz M. Case-Mix and cost differences between teaching and nonteaching hospitals. Med Care 1985;23:283-95.

25 Goldfarb MG, Coffey RM. Case-mix differences between teaching and nonteaching hospitals. Inquiry 1987;24:68-84.

26 Khuri SF, Najjar SF, Daley J, et al. Comparison of surgical outcomes between teaching and nonteaching hospitals in the Department of Veterans Affairs. Ann Surg 2001;234:370-83.

27 Oleske DM, Glandon GL, Giacomelli GJ, et al. The cesarean birth rate: influence of hospital teaching status. Health Serv Res 1991;26:325-37.

28 Zimmerman JE, Shortell SM, Knaus WA, et al. Value and cost of teaching hospitals: a prospective, multicenter, inception cohort study. Crit Care Med 1993;21:1432-42.

29 Ayanian JZ, Weissman JS, Chasan-Taber S, et al. Quality of care for two common illnesses in teaching and nonteaching hospitals. Health Aff 1998;17:194-205.

30 Taylor DH, Whellan DJ, Sloan FA. Effects of admission to a teaching hospital on the cost and quality of care for Medicare beneficiaries. $N$ Engl J Med 1999;340:293-9.

31 Ayanian JZ, Weissman JS. Teaching hospitals and quality of care: a review of the literature. Milbank Q 2002;80:569-93.

32 Burke LG, Frakt AB, Khullar D, et al. Association between teaching status and mortality in US hospitals. JAMA 2017;317:2105-13.

33 Hoxha I, Braha M, Syrogiannouli L, et al. Caesarean section in uninsured women in the USA: systematic review and meta-analysis. BMJ Open 2019;9:e025356.

34 Hoxha I, Syrogiannouli L, Braha M, et al. Caesarean sections and private insurance: systematic review and meta-analysis. BMJ Open 2017;7:e016600.

35 Hoxha I, Sadiku F, Lama A, et al. Cesarean delivery and gender of delivering physicians: a systematic review and meta-analysis. Obstet Gynecol 2020;136:1170-8.

36 Dekkers OM, Vandenbroucke JP, Cevallos M, et al. COSMOS-E: guidance on conducting systematic reviews and meta-analyses of observational studies of etiology. PLoS Med 2019;16:e1002742.

37 Moher D, Liberati A, Tetzlaff J, et al. Preferred reporting items for systematic reviews and meta-analyses: the PRISMA statement. BM 2009;339:b2535.

38 Stroup DF, Berlin JA, Morton SC. Meta-Analysis of observational studies in epidemiology: a proposal for reporting. meta-analysis of observational studies in epidemiology (MOOSE) group. JAMA 2000;283:2008-12.
39 Robson MS. Classification of caesarean sections. Fetal Matern Med Rev 2001;12:23-39.

40 Vogel JP, Betrán AP, Vindevoghel N, et al. Use of the Robson classification to assess caesarean section trends in 21 countries: a secondary analysis of two who multicountry surveys. The Lancet Global Health 2015;3:e260-70.

41 Hayden JA, van der Windt DA, Cartwright JL, et al. Assessing bias in studies of prognostic factors. Ann Intern Med 2013;158:280-6.

42 DerSimonian R, Laird N. Meta-Analysis in clinical trials. Control Clin Trials 1986;7:177-88

43 Ayanian JZ, Weissman JS. Teaching hospitals and quality of care: a review of the literature. Milbank Quarterly 2002;80:569-93.

44 Sanchez-Ramos L, Moorhead RI, Kaunitz AM. Cesarean section rates in teaching hospitals: a national survey. Birth 1994;21:194-6.

45 Braveman $\mathrm{P}$, Egerter S, Edmonston $\mathrm{F}$, et al. Racial/Ethnic differences in the likelihood of cesarean delivery, California. Am J Public Health 1995;85:625-30.

46 Irwin DE, Savitz DA, Bowes WA, et al. Race, age, and cesarean delivery in a military population. Obstet Gynecol 1996;88:530-3

47 Chanrachakul B, Herabutya Y, Udomsubpayakul U. Epidemic of cesarean section at the general, private and university hospitals in Thailand. J Obstet Gynaecol Res 2000;26:357-61.

48 Murray SF. Relation between private health insurance and high rates of caesarean section in Chile: qualitative and quantitative study. BMJ 2000;321:1501-5.

49 David S, Mamelle N, Rivière O. Estimation of an expected caesarean section rate taking into account the case mix of a maternity hospital. analysis from the AUDIPOG Sentinelle network (France). obstetricians of AUDIPOG. Association of users of computerised files in Perinatalogy, obstetrics and gynaecology. BJOG 2001;108:919-26.

50 Garcia FA, Miller HB, Huggins GR. Effect of academic affiliation and obstetric volume on clinical outcome and cost of childbirth. Obstet Gynecol 2001;97:567-76.

51 Korst LM, Fridman M, Friedlich PS, et al. Hospital rates of maternal and neonatal infection in a low-risk population. Matern Child Health $J$ 2005;9:307-16.

52 Linton A, Peterson MR, Williams TV. Clinical case mix adjustment of cesarean delivery rates in U.S. military hospitals, 2002. Obstet Gynecol 2005;105:598-606.

53 Carayol M, Zeitlin J, Roman H, et al. Non-Clinical determinants of planned cesarean delivery in cases of term breech presentation in France. Acta Obstet Gynecol Scand 2007:86:1071-8.

54 Tamim H, El-Chemaly S, Nassar A, et al. Incidence and correlates of cesarean section in a capital city of a middle-income country. $J$ Perinat Med 2007;35:282-8.

55 Xirasagar S, Lin H-C. Maternal Request CS-Role of hospital teaching status and for-profit ownership. Eur J Obstet Gynecol Reprod Biol 2007;132:27-34.

56 Chen C-S, Lin H-C, Liu T-C, et al. Urbanization and the likelihood of a cesarean section. Eur J Obstet Gynecol Reprod Biol 2008; $141: 104-10$

57 Liu T-C, Lin H-C, Chen C-S, et al. Obstetrician gender and the likelihood of performing a maternal Request for a cesarean delivery. Eur J Obstet Gynecol Reprod Biol 2008;136:46-52.

58 Zhang J, Troendle J, Reddy UM, et al. Contemporary cesarean delivery practice in the United States. Am J Obstet Gynecol 2010;203:326.e1-326.e10.

59 Taljaard M, Donner A, Villar J, et al. Understanding the factors associated with differences in caesarean section rates at hospital level: the case of Latin America. Paediatr Perinat Epidemiol 2009:23:574-81.

60 Snyder CC, Wolfe KB, Loftin RW, et al. The influence of hospital type on induction of labor and mode of delivery. Am J Obstet Gynecol 2011;205:346.e1-346.e4.

61 Aman H, Negash S, Yusuf L. Cesarean delivery practices in teaching public and non-government/private $\mathrm{MCH}$ hospitals, Addis Ababa. Ethiopian Journal of Health Development 2014;28:22-8.

62 Stivanello E, Rucci P, Lenzi J, et al. Determinants of cesarean delivery: a classification tree analysis. BMC Pregnancy Childbirth 2014;14.

63 Bommarito KM, Gross GA, Willers DM, et al. The effect of clinical chorioamnionitis on cesarean delivery in the United States. Health Serv Res 2016;51:1879-95.

64 Kim SJ, Han K-T, Kim SJ, et al. Impact of a diagnosis-related group payment system on cesarean section in Korea. Health Policy 2016;120:596-603.

65 Meda IB, Millogo T, Baguiya A, et al. Rate of and factors associated with indications for cesarean deliveries: results of a national review in Burkina Faso. Int J Gynaecol Obstet 2016;135 Suppl 1:S51-7. 
66 Oner C, Catak B, Sutlu S. Effect of social factors on cesarean birth in primiparous women: a cross sectional study (social factors and cesarean birth). Iran J Public Health 2016;45:768-73.

67 Faisal-Cury A, Menezes PR, Quayle J, et al. The relationship between indicators of socioeconomic status and cesarean section in public hospitals. Rev. Saúde Pública 2017;51.

68 Lorthe E, Quere M, Sentilhes L, et al. Incidence and risk factors of caesarean section in preterm breech births: a population-based cohort study. Eur J Obstet Gynecol Reprod Biol 2017;212:37-43.

69 Clapp MA, James KE, Melamed A, et al. Hospital volume and cesarean delivery among low-risk women in a nationwide sample. $J$ Perinatol 2018;38:127-31.

70 Zbiri S, Rozenberg P, Goffinet F, et al. Cesarean delivery rate and staffing levels of the maternity unit. PLOS One 2018;13:e0207379.

71 Zimmo M, Laine K, Hassan S, et al. Differences in rates and odds for emergency caesarean section in six Palestinian hospitals: a population-based birth cohort study. BMJ Open 2018;8:e019509.

72 Zimmo MW, Laine K, Hassan S, et al. Caesarean section in Palestine using the Robson ten group classification system: a populationbased birth cohort study. BMJ Open 2018:8:e022875.
73 del Carmen GA, Stapleton S, Qadan M, et al. Does the day of the week predict a cesarean section? A statewide analysis. J Surg Res 2020;245:288-94.

74 Sinnott S-J, Brick A, Layte R, et al. National variation in caesarean section rates: a cross sectional study in Ireland. PLoS One 2016;11:e0156172.

75 McCusker J, Harris DR, Hosmer DW. Association of electronic feta monitoring during labor with cesarean section rate and with neonatal morbidity and mortality. Am J Public Health 1988;78:1170-4.

76 Pel M, Heres MHB, Hart AAM, et al. Provider-associated factors in obstetric interventions. Eur J Obstet Gynecol Reprod Biol 1995;61:129-34.

77 Cheng Y, Carpenter A, Main E. 794: large hospital-level variation in cesarean delivery rates during induction of labor. Am J Obstet Gynecol 2015;212:S384.

78 Korst LM, Gornbein JA, Gregory KD. Rethinking the cesarean rate: how pregnancy complications may affect interhospital comparisons. Med Care 2005;43:237-45.

79 Bonciani M, Lupi B, Nuti S. Performance evaluation in healthcare: the experience of maternity pathway from Tuscany to the Italian network of regions. Ital J Pediatr 2014;40:420. 